\title{
Recrystallized thin-film silicon solar cell on graphite substrate with laser single side contact and hydrogen passivation
}

\author{
Da Li ${ }^{1}$,a , Stephan Wittmann ${ }^{1}$, Thomas Kunz ${ }^{1}$, Taimoor Ahmad ${ }^{1}$, Nidia Gawehns ${ }^{1}$, Maik T. Hessmann ${ }^{1}$, Jan Ebser ${ }^{2}$, \\ Barbara Terheiden ${ }^{2}$, Richard Auer ${ }^{1}$, and Christoph J. Brabec ${ }^{1,3}$ \\ 1 Bavarian Center for Applied Energy Research (ZAE Bayern), Haberstr. 2a, 91058 Erlangen, Germany \\ 2 Department of Physics, University of Konstanz, Box 676, 78457 Konstanz, Germany \\ 3 Institute of Materials for Electronics and Energy Technology (i-MEET), University of Erlangen-Nuremberg, Martensstr. 7, \\ 91058 Erlangen, Germany
}

Received: 15 January 2015 / Received in final form: 26 April 2015 / Accepted: 4 May 2015

Published online: 21 May 2015

(C) Li et al., published by EDP Sciences, 2015

\begin{abstract}
Laser single side contact formation (LSSC) and the hydrogen passivation process are studied and developed for crystalline silicon thin film (CSiTF) solar cells on graphite substrates. The results demonstrate that these two methods can improve cell performance by increasing the open circuit voltage and fill factor. In comparison with our previous work, we have achieved an increase of $3.4 \%$ absolute cell efficiency for a $40 \mu \mathrm{m}$ thick $4 \mathrm{~cm}^{2}$ aperture area silicon thin film solar cell on graphite substrate. Current density-voltage $(J-V)$ measurement, quantum efficiency (QE) and light beam induced current (LBiC) are used as characterization methods.
\end{abstract}

For crystalline silicon thin film (CSiTF) solar cells on the foreign substrates, a recrystallization process plays an important role in enlarging the size of the silicon grains in order to reduce the density of the electrically active defects and increase the cell efficiencies, and hence the electron-beam recrystallization $[1,2]$, zone melting recrystallization (ZMR) $[3,4]$ and laser recrystallization [5-9] are widely developed [10-13]. Foreign substrate materials, such as ceramics [14-16] and graphite [17], are generally used for CSiTF cell fabrication with the high temperature approach. Schillinger et al. [18] described a CSiTF cell concept on zircon ceramic substrates using ZMR reached $8.1 \%$ conversion efficiency. Graphite substrates can be processed at high temperature. Moreover, they are available at high purity and with thermal expansion characteristics similar to silicon. While standard graphite types will not meet the cost requirements, developments for low-cost types such as biogenic substrates are in progress [19].

In previous work, we have reported a best laboratory cell efficiency of $6.8 \%$ with the $4 \mathrm{~cm}^{2}$ aperture area on the graphite substrate [20]. That cell concept is shown in Figure 1a. The laser edge isolation (LEI) technique was applied to avoid the parasitic electrical connection between the front and back contacts. This technique was proved to be a convenient and accurate method instead of the plasma etching process. By using the LEI technique,

\footnotetext{
${ }^{a}$ e-mail: da.li@zae-bayern.de
}

the best parallel resistance, approximately $1.7 \Omega \mathrm{m}^{2}$, was achieved.

Much effort has been devoted to the metallization of CSiTF solar cells on foreign substrates. Stocks et al. [21] presented the concept of CSiTF solar cells with base frontcontacts. Hebling et al. [22] realized the concept by using photolithography. Meanwhile, Lüdemann et al. [23] realized base front-contacts silicon solar cells on a $\mathrm{SiC}$ intermediate layer with a graphite substrate. Furthermore, Rachow et al. [24] named the concept as single side contact formation. Different microstructures of single side concepts can be formed using photolithography [21] or reactive ion etching (RIE) [25]. However, the photolithography is an expensive technology, whereas a typical RIE system consists of a vacuum chamber and a plasma generation system. Due to the development of laser techniques, laser processes are nowadays widely used in thin film solar cell fabric processing. Such techniques can now be used to complete a solar cell with single side contact formation in fewer steps.

In this paper, we developed the cell concept on graphite substrates as shown in Figure 1b. The current density-voltage $(J-V)$ curves and quantum efficiency (QE) measurements show the improvements of open circuit voltage $\left(V_{\text {oc }}\right)$, fill factor $(F F)$, cell efficiency $(\eta)$, and quantum efficiency due to the hydrogen bulk passivation process $[26,27]$ and laser single side contact (LSSC) formation. 


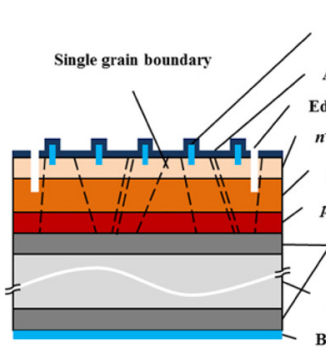

(a)

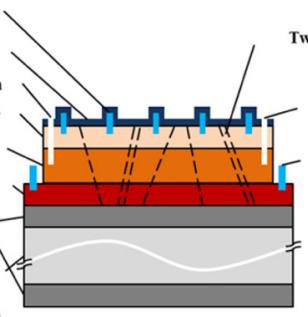

(b)

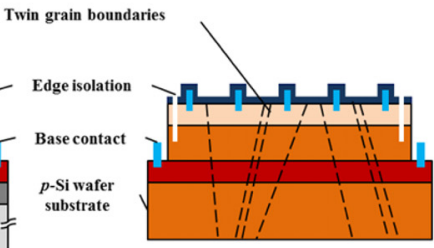

(c)

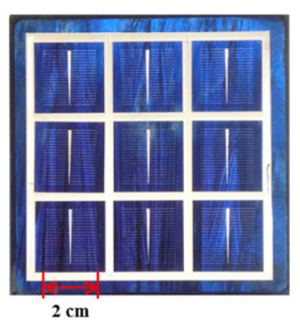

(d)

Fig. 1. The three different Si thin-film solar cell designs were studied. (a) The cell in previous work is based on front and back contacts. (b) The new design in this paper is based on laser single side front contacts (LSSC). (c) The reference cells are based on $p$-type Si wafer. The layers are not to scale. (d) Top view of batch Gra. C, on which are the nine cells with the graphite substrate. The cell No. 5 is in the center.

The combined solar cell process is carried out at a low temperature $\left(<350{ }^{\circ} \mathrm{C}\right)$. The diffusion length was characterized using light beam induced current (LBiC) measurement and simulated by PC1D [28]. Here we report our $10.2 \%$ cell efficiency of a $40 \mu \mathrm{m}$ thick and $4 \mathrm{~cm}^{2}$ aperture area CSiTF solar cell on graphite substrate.

\section{Experimental}

\subsection{Solar cell design and processing}

Three different cell designs (Figs. 1a-1c) were studied. The designs illustrated in Figures 1a and $1 \mathrm{~b}$ are based on the use of graphite as a foreign substrate, with different concepts of base contact formation. In designing Figure 1c, a multi-crystalline Si-wafer was chosen as a base material for reference purposes, because recrystallized silicon layers on graphite substrates have a similar grain size to typical multi-crystalline Si-wafers. Results from the design of Figure 1a have been described in a previous work [20], while the other two designs are investigated in this work.

For the foreign substrates (Figs. 1a and 1b), high purity graphite substrates ("FP479", Schunk Kohlenstofftechnik $\mathrm{GmbH}$ ) with a size of $10 \mathrm{~cm} \times 10 \mathrm{~cm} \times 2 \mathrm{~mm}$ were used. The SiC layer with a thickness of $10 \mu \mathrm{m}$ was deposited using a hot-wall chemical vapor deposition, which covered both surfaces of the substrate to prevent the diffusion of impurities. Then, a $p^{+}$-Si layer (acceptor concentration of $4 \times 10^{18} \mathrm{~cm}^{-3}$ ) approximately $20 \mu \mathrm{m}$ thick was deposited on top of the $\mathrm{SiC}$ layer using a convectionassisted chemical vapor deposition (CoCVD) [29]. The $p^{+}$-Si layers served as a seed and back surface field layer. The ZMR process was applied to enlarge the size of the silicon grains from the micrometer to the millimeter range. Thus, a random texture surface was formed due to the various crystalline silicon directions [4].

For the reference substrate (Fig. 1c), the $p^{+}$-Si layer had the concentration of $4 \times 10^{18} \mathrm{~cm}^{-3}$ and was epitaxially grown directly onto the wafer substrate.

Further processing was the same for both the foreign substrate and the Si-wafer substrate. A $20 \mu \mathrm{m}$ thick epitaxial $p$-Si base layer was applied over the $p^{+}-$Si layer. This $p$-Si layer had a boron doping concentration of about
Table 1. Sample list. $\mathrm{H}^{+}$denotes the hydrogen passivation process.

\begin{tabular}{ccccc}
\hline Batches & Substrate & Contacts & $\begin{array}{c}\mathrm{H}^{+} \\
{[\text {Yes/No } /}\end{array}$ & $\begin{array}{c}\text { Duration } \\
(\mathrm{min})\end{array}$ \\
\hline Gra. A & Graphite & Both sides & No & - \\
Gra. B & Graphite & LSSC & No & - \\
Gra. C & Graphite & LSSC & Yes & 50 \\
Waf. A & $p$-Si wafer & Both sides & No & - \\
Waf. B & $p$-Si wafer & LSSC & No & - \\
Waf. C & $p$-Si wafer & LSSC & Yes & 50 \\
Waf. D & $p$-Si wafer & LSSC & Yes & 50 \\
Waf. E & $p$-Si wafer & LSSC & Yes & 50 \\
\hline
\end{tabular}

$2 \times 10^{16} \mathrm{~cm}^{-3}$. The $n^{+}$-Si emitter was formed by spin on doping (SOD) of a phosphorous solution followed by rapid thermal processing (RTP) in a furnace [30]. The sheet resistance is in the range from 80 to $120 \Omega$ /square. The laser edge isolation process was applied directly after the removal of the phosphorous glass [20]. The metallization of the front contacts were formed by electron beam evaporation of $\mathrm{Ti}, \mathrm{Pd}$ and $\mathrm{Ag}(30 \mathrm{~nm}, 30 \mathrm{~nm}$, and $5 \mu \mathrm{m}$ thick, respectively). Finally, using plasma-enhanced chemical vapor deposition (PECVD) we deposited a silicon nitride layer with a thickness of $75 \mathrm{~nm}$, which served as an antireflection coating. The total thickness of the silicon layers was about $40 \mu \mathrm{m}$. As shown in Figure 1d, nine cells, each with a size of $2 \mathrm{~cm} \times 2 \mathrm{~cm}$, have been fabricated on the $10 \mathrm{~cm} \times 10 \mathrm{~cm}$ graphite substrate.

\subsection{Sample batches}

As shown in Table 1, we prepared and studied eight different batches for the comparison of LSSC formation and hydrogen passivation process. The batches based on the graphite substrates are named Gra. A, B, and C, whereas the reference batches based on the $p$-type Si-wafers are named Waf. A, B, C, D, and E. The batches denoted by different capital letters correspond to the different processing sequences as shown in Figures 2 and 3:

- Gra. A and Waf. A are the samples with base contacts on the back of the solar cells. They are based on the design of Figure 1a. The base contact is formed by 


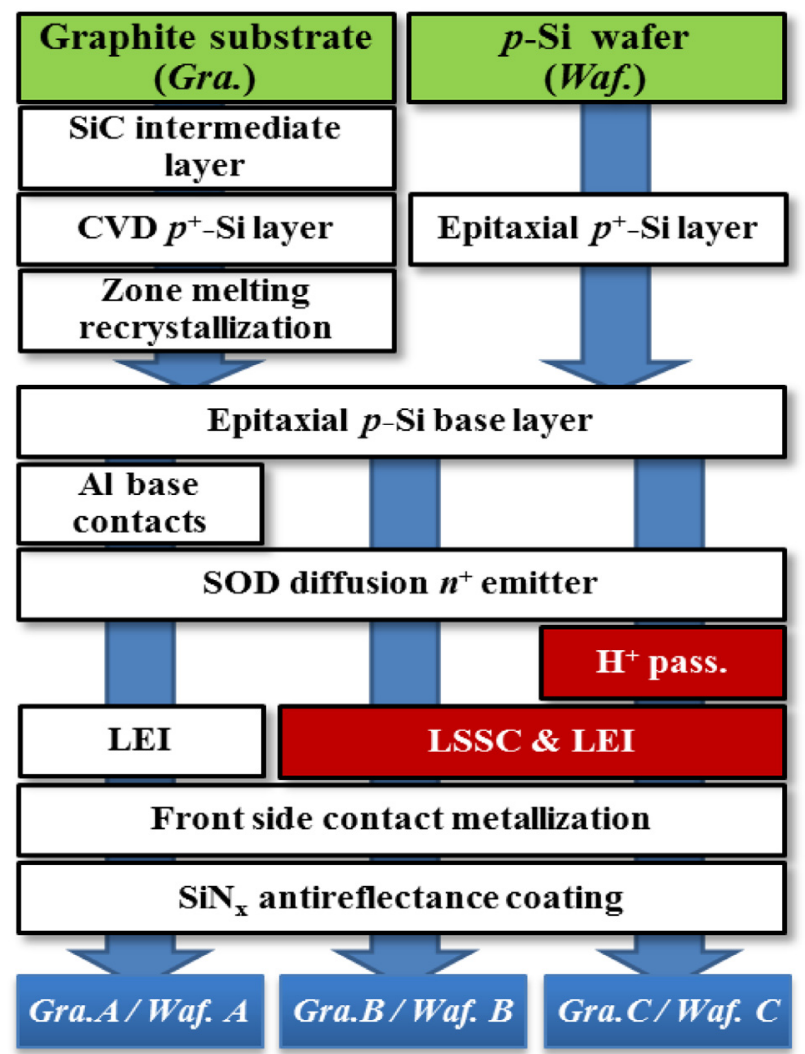

Fig. 2. Processing sequence of the cells. Eight solar cell batches are prepared. Gra. denotes the cells on graphite substrate and Waf. denotes the cells on wafers as reference. Laser edge isolation (LEI), laser single side contact (LSSC) and hydrogen bulk passivation $\left(\mathrm{H}^{+}\right.$pass.) were applied in the cell process. Batches Gra. A-C on graphite substrates, reference batches Waf. A-C on Si wafers with the same processing after ZMR as Gra. A-C.

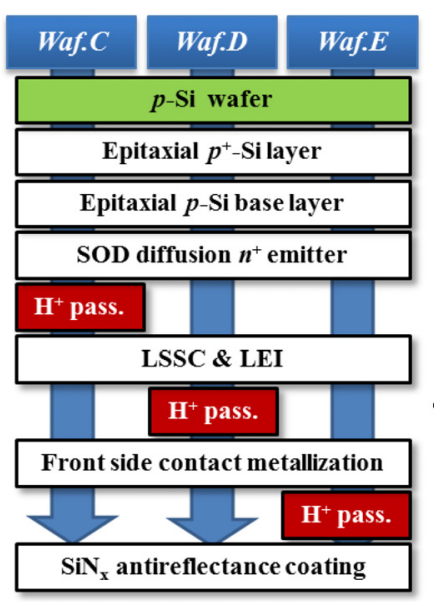

(a)

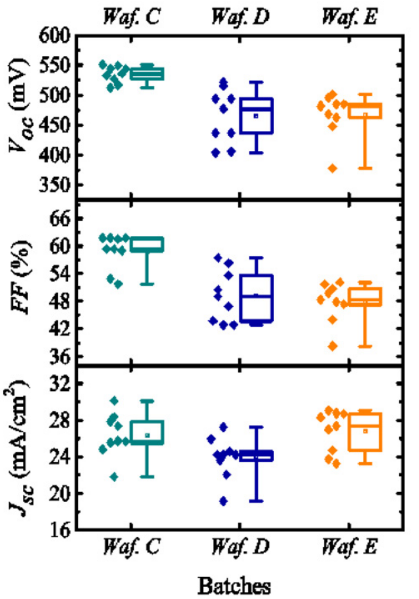

(b)
Fig. 3. Reference batches Waf. C-E on Si wafer with a different sequence of hydrogen passivation. (a) Processing sequence of the cells. (b) Open circuit voltage $V_{\text {oc }}$ (top), fill factor $F F$ (middle) and current density $J_{\mathrm{sc}}$ (bottom) due to the three different hydrogen passivation processes. a $5 \mu \mathrm{m}$ thick aluminum layer, which was deposited on the back of the substrate. Hydrogen passivation is not used in these batches.

- Gra. B and Waf. B's base contacts were formed from the front using LSSC. They are based on the design of Figure 1b, but without the hydrogen passivation process.

- Gra. C and Waf. C-E are with LSSC and the hydrogen passivation process. Gra. C is based on the design of Figure 1b. Waf. C-E are based on the design of Figure 1c.

\subsection{Laser single side contact}

Based on the development of laser technology, we fabricated the base contacts on the front using a laser process, i.e. laser single side contacts instead of the $\mathrm{Al}$ back base contacts. Each cell from batches Gra. A and Waf. A had an aluminum base contact, which was evaporated on the back. Here we used a Nd: $\mathrm{YVO}_{4}$ laser (Rofin Power Line LP20, wavelength $1064 \mathrm{~nm}$ ) to make approximately $30 \mu \mathrm{m}$ deep trenches into the samples down to the $p^{+}$-Si layer and to obtain $3 \mathrm{~mm}$ wide contact stripes around the cells. After the laser trenching and LEI process, we evaporated the emitter contacts and the base contacts on the front at the same time and with the same metals $\mathrm{Ti}, \mathrm{Pd}$, and $\mathrm{Ag}$.

\subsection{Hydrogen passivation}

The bulk recombination centers in the CSiTF solar cells can be restrained using a hydrogen passivation process, which is dependent on time and temperature. According to reference [27], the hydrogen passivation process needs less process time at high temperatures than at low temperatures. If the process temperature is $600{ }^{\circ} \mathrm{C}$, the necessary reaction time is only about $5 \mathrm{~min}$. In our case, the samples were put into the chamber at $350{ }^{\circ} \mathrm{C}$ for $50 \mathrm{~min}$ (microwave power: $1000 \mathrm{~W}$, pressure: $0.04 \mathrm{mbar}$ and hydrogen as the precursor). Experiments were carried out using a PECVD system of Roth and Rau AK1000 with microwave excitation frequency at $2.45 \mathrm{GHz}$.

The process sequence is critical for hydrogen passivation. As shown in Figure 3, in order to determine the best fabrication sequence of the hydrogen passivation, we prepared and compared three different process sequences. For this study, the reference system on wafer substrates was used in order to exclude influences from varying defect structures, as they may result from the recrystallization process. The hydrogen passivation process was included after

- the SOD diffusion processing (Waf. C);

- the laser trenching and LEI (Waf. D);

- the metallization processing (Waf. E).

\subsection{Cell characterization}

Internal quantum efficiency (IQE) and reflectance are measured using the pv-tools solar cell analysis system 
Table 2. Cell parameters. Open circuit parallel resistance $\left(R_{\mathrm{p}}\right)$, series resistance $\left(R_{\mathrm{s}}\right)$, voltage $\left(V_{\mathrm{oc}}\right)$, current density $\left(J_{\mathrm{sc}}\right)$, fill factor $(F F)$, and efficiency $(\eta)$.

\begin{tabular}{cccccccc}
\hline Batches & $\begin{array}{c}\text { Avg. } \\
R_{\mathrm{p}} \\
\left(\Omega \mathrm{m}^{2}\right)\end{array}$ & $\begin{array}{c}\text { Avg. } \\
R_{\mathrm{s}} \\
\left(\Omega \mathrm{cm}^{2}\right)\end{array}$ & $\begin{array}{c}\text { Avg. } \\
V_{\mathrm{oc}}\end{array}$ & $\begin{array}{c}\text { Avg. } \\
J_{\mathrm{sc}} \\
\left(\mathrm{mA} / \mathrm{cm}^{2}\right)\end{array}$ & $\begin{array}{c}\text { Avg. } \\
F F \\
(\%)\end{array}$ & $\begin{array}{c}\text { Avg. } \\
(\%)\end{array}$ & $\begin{array}{c}\text { Best } \\
(\%)\end{array}$ \\
\hline Gra. A & 1.53 & 1.52 & 426 & 21.3 & 56.7 & 5.18 & 6.79 \\
Gra. B & 1.97 & 1.06 & 469 & 234 & 66.5 & 7.33 & 7.81 \\
Gra. C & 2.47 & 1.05 & 499 & 262 & 67.7 & 8.86 & 10.2 \\
Waf. A & 1.08 & 2.22 & 450 & 255 & 49.0 & 5.74 & 7.68 \\
Waf. B & 2.51 & 2.77 & 501 & 250 & 57.0 & 7.18 & 8.19 \\
Waf. C & 3.18 & 2.85 & 534 & 263 & 58.7 & 8.29 & 10.1 \\
Waf. D & 0.33 & 3.24 & 465 & 23.9 & 49.2 & 5.52 & 7.77 \\
Waf. E & 0.03 & 2.21 & 467 & 26.7 & 47.7 & 5.97 & 7.14 \\
\hline
\end{tabular}

LOANA at the University of Konstanz and using the Enlitech solar cell analysis system QE-R at i-MEET. Light beam induced current ( $\mathrm{LBiC})$ measurements were carried out by using Semilab WT2000, which has four light sources (976 nm, $951 \mathrm{~nm}, 846 \mathrm{~nm}$ and $662 \mathrm{~nm})$. The diffusion length was calculated from the $\mathrm{LBiC}$ measurements at various wavelengths.

\section{Results and discussion}

\section{$2.1 \mathrm{~J}-\mathrm{V}$ characterization}

Table 2 lists the parameters obtained from the illuminated and dark $J-V$ measurements. We arranged the $J_{\mathrm{sc}}$, $V_{\text {oc }}$ and $F F$ data of all the samples in the form of a box chart, as shown in Figure $3 \mathrm{~b}$. These results were used to identify the best hydrogen passivation sequence, which is described in Section 2.1.1. Furthermore, we observed significant improvement in $V_{\mathrm{oc}}$ and $F F$ with hydrogen bulk passivation and LSSC formation in Figure 4, which is described in Section 2.1.2.

\subsubsection{Hydrogen passivation sequence on reference batches}

Comparing the results of these three batches (Waf. CE) in Figure 3b and Table 2, we found the best hydrogen passivation sequence is the hydrogen bulk passivation process of Waf. C. This batch has the highest average values of $R_{\mathrm{p}}, V_{\mathrm{oc}}$, and $F F$ among the three batches.

In the case of Waf. D, the hydrogen passivation was applied after the laser trenching and LEI process. This process sequence resulted in lower cell performance than Waf. C, which is most probably due to laser induced defects. Slaoui et al. [31] reported the hydrogen passivation of laser induced defects, which demonstrated that the quality of the hydrogen passivation highly depends on the temperature of the passivation process.

In the case of Waf. E, the contacts were already evaporated before the hydrogen passivation process. As shown in Table 2, this process sequence resulted in extremely lower average parallel resistance $R_{\mathrm{p}}\left(\bar{R}_{\mathrm{p}}\right)$ than Waf. C, which further resulted in a low average $F F(\overline{F F})$.

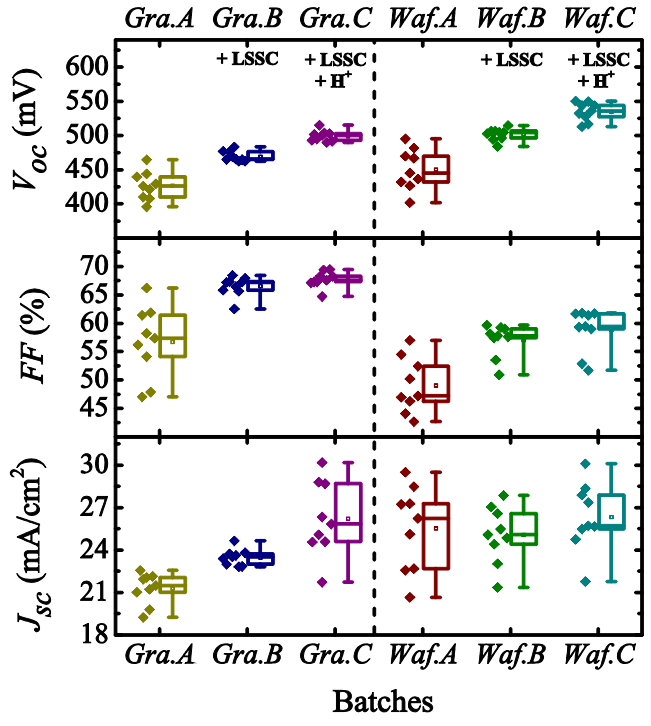

Fig. 4. $V_{\mathrm{oc}}$ (top), FF (middle) and $J_{\mathrm{sc}}$ (bottom) due to the both-side contact, LSSC formation (i.e. +LSSC), and hydrogen passivation processes (i.e. $+\mathrm{H}^{+}$).

This was assumed due to the fact that the front contacts $(\mathrm{Ag} / \mathrm{Pd} / \mathrm{Ti})$ penetrated through the thin emitter layer into the base layer during the passivation process at $350{ }^{\circ} \mathrm{C}[32]$.

Accordingly, the best hydrogen passivation sequence was made directly after the phosphor diffusion process, which was also applied to fabricate Gra. C.

\subsubsection{Batches with hydrogen passivation and LSSC on graphite substrates}

In order to confirm the improvement by LSSC formation and hydrogen passivation, we further compared the results of the graphite substrate batches (Gra. A-C) and the reference batches (Waf. A-C). There are three different formations as shown in Figure 2.

As shown in Figure 4, both the graphite-based (Gra.) and reference (Waf.) batches exhibit similar variations in 


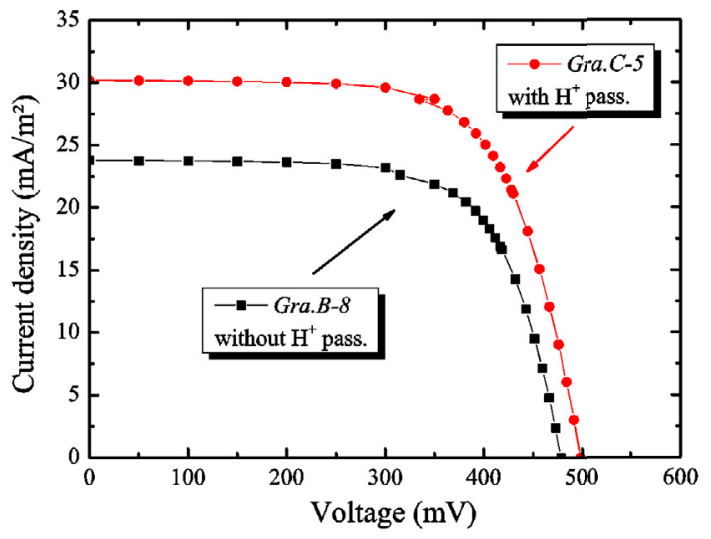

Fig. 5. $J-V$ curves of the cells Gra. B-8 and Gra. C-5. (i.e. LSSC formation without (Gra. B) and with (Gra. C) hydrogen passivation).

$\bar{V}_{\text {oc }}$ and $\overline{F F}$, which can be described by:

$$
\begin{aligned}
&\left.\bar{V}_{\text {oc }} \text { (Gra. A }\right)<\bar{V}_{\text {oc }} \text { (Gra. B) }<\bar{V}_{\text {oc }} \text { (Gra. C) } \\
&\left.\left.\bar{V}_{\text {oc }} \text { (Waf. A }\right)<\bar{V}_{\text {oc }} \text { (Waf. B }\right)<\bar{V}_{\text {oc }} \text { (Waf. C) } \\
&\overline{F F} \text { (Gra. A })<\overline{F F} \text { (Gra. B) }<\overline{F F} \text { (Gra. C) } \\
&\overline{F F} \text { (Waf. A })<\overline{F F} \text { (Waf. B) }<\overline{F F} \text { (Waf. C). }
\end{aligned}
$$

Those inequalities indicate that the batches with LSSC formation have better performance than the batches with both sides contact formation. The possible reason is that the LSSC formation had less recombination losses than the both-side contact formation, since the collected current bypassed the intermediate layer and the graphite substrate. Moreover, the hydrogen passivation reduced the bulk recombination, and therefore the batches, with both LSSC formation and hydrogen passivation applied have the best performance in $\bar{V}_{\text {oc }}$ and $\overline{F F}$. We also observed that the $\bar{J}_{\text {sc }}$ of the cells based on graphite substrates had the same trend:

$$
\bar{J}_{\text {sc }}(\text { Gra. A })<\bar{J}_{\text {sc }}(\text { Gra. B })<\bar{J}_{\text {sc }}(\text { Gra. C) } .
$$

We observed that the values of $\bar{J}_{\mathrm{sc}}$ were improved using the LSSC formation by comparison $\bar{J}_{\mathrm{sc}}$ (Gra. A) and $\bar{J}_{\mathrm{sc}}$ (Gra. B). We also observed $\bar{J}_{\mathrm{sc}}$ (Gra. C) was the highest due to the applied LSSC and hydrogen bulk passivation. However, the values of $\bar{J}_{\mathrm{sc}}$ of the reference cells based on mc-Si wafers did not have the same trend. According to the process sequence, as shown in Figure 2, the reason can be that the reference cells were with neither an intermediate layer nor a ZMR process. Moreover, the back surfaces of the reference cells were not passivated. Therefore, the improvement using hydrogen bulk passivation cannot counteract the detrimental effect of the back surface recombination.

Figure 5 shows illuminated $J-V$ curves of the best cells from Gra. B and C. The best cell in Gra. C (cell No. 5) i.e. Gra. C-5, has $3.17 \Omega \mathrm{m}^{2}$ parallel resistance, $502 \mathrm{mV} V_{\mathrm{Oc}}$ and $67.2 \%$ fill factor. In contrast, the best cell in Gra. B i.e. Gra. B-8, without the hydrogen bulk passivation has

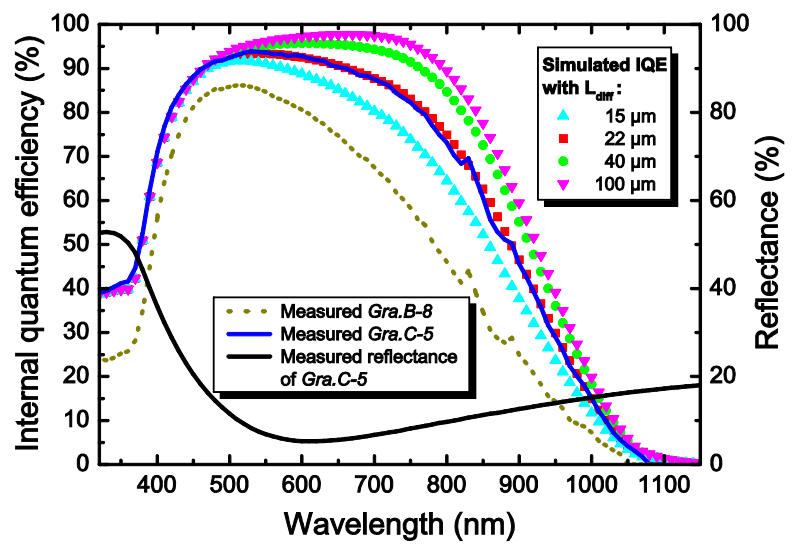

Fig. 6. The reflectance, measured and simulated IQE curves of the cell Gra. C-5. The measured IQE of the cell Gra. B-8 is plotted for comparison. The bulk lifetime was varied for fitting. The IQE is simulated by PC1D for diffusion lengths with 15 , 22,40 , and $100 \mu \mathrm{m}$.

Table 3. PC1D parameters and simulation results. The parameters device area, base contact, thickness, $p$-type background doping and first rear diffusion were chosen according to cell Gra. C-5. ${ }^{*}$ The parameters were varied for fitting IQE.

\begin{tabular}{cccc}
\hline & Parameters & Results & Units \\
\hline \multirow{4}{*}{ Input } & Device area & 4 & $\mathrm{~cm}^{2}$ \\
& Base contact & 0.7125 & $\Omega$ \\
& Thickness & 40 & $\mu \mathrm{m}$ \\
& $p$-type background doping & $2 \times 10^{16}$ & $\mathrm{~cm}^{-3}$ \\
& Sheet Resistance & 112 & $\Omega / \mathrm{square}^{-3}$ \\
& 1st rear diffusion & $4 \times 10^{18}$ & $\mathrm{~cm}^{-3}$ \\
& Bulk recombination* & 0.2 & $\mu \mathrm{s}$ \\
Output & Front surface recombination* & $8 \times 10^{5}$ & $\mathrm{~cm} / \mathrm{s}$ \\
\cline { 2 - 4 } & $I_{\mathrm{sc}}$ & 0.103 & $\mathrm{~A}$ \\
& $V_{\mathrm{oc}}$ & 567.9 & $\mathrm{mV}$ \\
& Efficiency & 10.15 & $\%$ \\
\hline
\end{tabular}

less $V_{\mathrm{oc}}$ and $J_{\mathrm{sc}}$ mainly due to the defects in the bulk. To date, we have achieved a cell efficiency of $10.2 \%$, which is the highest efficiency of a $40 \mu \mathrm{m}$ thick crystalline silicon solar cell on graphite substrate with a $4 \mathrm{~cm}^{2}$ aperture area.

\subsection{Quantum efficiency}

Figure 6 shows the measured IQE of Gra. B-8 and Gra. C-5, the simulated IQE using PC1D and the reflectance of the Gra. C-5. Gra. B-8 had the shorter diffusion length and lower quantum efficiency than Gra. C-5 due to the surface and bulk recombination without the hydrogen bulk passivation. The simulation parameters are shown in Table 3 . The simulation results are in very good agreement with the measured curve. The main difference is that the simulated $V_{\text {oc }}$ is about $50 \mathrm{mV}$ higher than the measured one. This may be a result of spatial non-uniformities due to various crystal grains, which cannot be accounted for in 1-dimensional simulations using PC1D. 
The anti-reflection coating layers made up of silicon nitride $75 \mathrm{~nm}$ thick. The refractive index of the layer is approximately 2. Figure 6 shows that the minimum reflection of the reflectance curve is close to $600 \mathrm{~nm}$, since we fabricated it close to the maximum of the number of incident photons. The $\mathrm{SiN}_{x}$ layers were formed at a low temperature without optimized passivation properties, which cannot reduce the surface recombination in the emitter. Therefore, as shown in the IQE curves, that was assumed to be the main reason why the cell has a spectral response below $90 \%$ in the range from $400 \mathrm{~nm}$ to $550 \mathrm{~nm}$. In the range from $550 \mathrm{~nm}$ to $1000 \mathrm{~nm}$, the IQE goes down gradually due to the bulk and rear recombination loss. In addition, the QE results also reveal that, there are some possibilities for improving the cell performance further, such as by lowering the surface recombination and by optimizing the bulk passivation process.

\subsection{Diffusion length}

The measured average diffusion length of Gra. C-5 is about $120 \mu \mathrm{m}$ using the $\mathrm{LBiC}$, however, the value is larger than the cell thickness, since these three wavelengths (976 nm, $951 \mathrm{~nm}$ and $846 \mathrm{~nm}$ ) have the longer penetration lengths than the $40 \mu \mathrm{m}$ thick active layers of the cells.

Therefore, we obtained the effective diffusion length of the CSiTF solar cell by using PC1D. The real thickness of the cell was included into the PC1D model. We used this model to fit the measured IQE. The simulated IQE characteristic curves for diffusion lengths were 15, 22, 40, and $100 \mu \mathrm{m}$, respectively. The effective diffusion length was varied for the fitting and is approximately $22 \mu \mathrm{m}$. This result again demonstrates that a surface passivation process and a higher layer quality are necessary for further increasing cell efficiency.

\section{Conclusions}

In this work, we have presented a new strategy to improve CSiTF solar cell on graphite substrates, using the laser single side contact formation and the hydrogen bulk passivation process at a low temperature. Both methods result in an increase of $V_{\mathrm{oc}}$ and $F F$. The recombination losses in the bulk and the surface are the main limitations on the cell performance. We achieved $10.2 \%$ cell efficiency on an aperture area of $4 \mathrm{~cm}^{2}$.

By comparing different sequences with $J-V$ measurement, we also found the best sequence for inclusion of the hydrogen bulk passivation. This significantly improved the cell performance.

We found that one-side contact with LSSC formation is better than front and back contact formation for CSiTF solar cells on graphite substrates. Furthermore, the cell fabrication process can be simplified by making the metallization of all contacts at the same time. The successful application of the LSSC indicates a potential improvement: it is possible to obtain good cell performance at a cost-effective price, while all contacts are on the front side and the impact by substrates is reduced using the LSSC formation. Not only for the CSiTF solar cells on graphite substrates, but we also expect that the LSSC strategy and the best hydrogen bulk passivation process sequence can be applied for the cells based on other high temperature foreign substrates.

So far, a $\mathrm{SiO}_{x}$ intermediate layer is supposed to provide a better quality of surface passivation than a SiC layer [33]. In addition, the batches have not included optimum design of metal grids, light trapping, surface passivation or local diffusion. Thus, the results of both $\mathrm{LBiC}$ and QE show possibilities for further improvement.

The authors gratefully acknowledge funding by the German Federal Ministry for the Environment, Nature Conservation and Nuclear safety (BMU) under contract No. 0325031B. We thank Dr. Stefan Janz, Fraunhofer ISE Freiburg, for the recrystallization of the silicon layers.

\section{References}

1. D. Amkreutz, J. Müller, M. Schmidt, T. Hänel, T.F. Schulze, Prog. Photovolt.: Res. Appl. 19, 937 (2011)

2. J. Haschke, D. Amkreutz, L. Korte, F. Ruske, B. Rech, Sol. Energy Mater. Sol. Cells 128, 190 (2014)

3. A.M. Barnett, R.B. Hall, J.A. Rand, C.L. Kendall, D.H. Ford, Sol. Energy Mater. 23, 164 (1991)

4. T. Kieliba. University of Konstanz, 2006

5. M. Weizman, H. Rhein, J. Dore, S. Gall, C. Klimm, G. Andrä, C. Schultz, F. Fink, B. Rau, R. Schlatmann, Sol. Energy Mater. Sol. Cells 120, 521 (2014)

6. J. Dore, D. Ong, S. Varlamov, R. Egan, M.A. Green, IEEE J. Photovolt. 4, 33 (2014)

7. J. Dore, R. Evans, U. Schubert, B.D. Eggleston, D. Ong, K. Kim, J. Huang, O. Kunz, M. Keevers, R. Egan, S. Varlamov, M.A. Green, Prog. Photovolt.: Res. Appl. 21, 1377 (2013)

8. G. Andrä, F. Falk, Phys. Stat. Sol. C 5, 3221 (2008)

9. S. Kühnapfel, N.H. Nickel, S. Gall, M. Klaus, C. Genzel, B. Rech, D. Amkreutz, Thin Solid Films 576, 68 (2015)

10. K.R. Catchpole, M.J. McCann, K.J. Weber, A.W. Blakers, Sol. Energy Mater. Sol. Cells 68, 173 (2001)

11. R. Brendel, Thin-film Crystalline Silicon Solar Cells: Physics and Technology (Wiley-Vch GmbH \& Co. KGaA, Weinheim, 2003)

12. J. Poortmans, V. Arkhipov, Thin Film Solar Cells: Fabrication, Characterization and Applications (John Wiley \& Sons, 2006)

13. C. Becker, D. Amkreutz, T. Sontheimer, V. Preidel, D. Lockau, J. Haschke, L. Jogschies, C. Klimm, J.J. Merkel, P. Plocica, S. Steffens, B. Rech, Sol. Energy Mater. Sol. Cells 119, 112 (2013)

14. A. Focsa, I. Gordon, J.M. Auger, A. Slaoui, G. Beaucarne, J. Poortmans, C. Maurice, Renew. Energy 33, 267 (2008)

15. T. Kunz, V. Gazuz, N. Gawehns, I. Burkert, M.T. Hessmann, R. Auer, in Proceedings of 24th European Photovoltaic Solar Energy Conference and Exhibition, Hamburg, Germany, 2009, p. 2553

16. S. Janz, P. Löper, M. Schnabel, Mater. Sci. Eng. B 178, 542 (2013) 
17. T. Kunz, M.T. Hessmann, R. Auer, A. Bochmann, S. Christiansen, C.J. Brabec, J. Cryst. Growth 357, 20 (2012)

18. K. Schillinger, S. Janz, S. Reber, in IEEE 39th Photovoltaic Specialists Conference, Tampa, USA, 2013, p. 1784

19. T. Kunz, R. Auer, ZAE Bayern, Report No. FKZ 0325031B, 2013

20. T. Kunz, V. Gazuz, M.T. Hessmann, N. Gawehns, I. Burkert, C.J. Brabec, Sol. Energy Mater. Sol. Cells 95, 2454 (2011)

21. M.J. Stocks, A. Cuevas, A.W. Blakers, Prog. Photovolt.: Res. Appl. 4, 35 (1996)

22. C. Hebling, S.W. Glunz, C. Schetter, J. Knobloch, A. Räuber, Sol. Energy Mater. Sol. Cells 48, 335 (1997)

23. R. Lüdemann, S. Schaefer, C. Schule, C. Hebling, in Proceedings of the 26th IEEE Photovoltaics Specialist Conference, Anaheim, USA, 1997, p. 159

24. T. Rachow, M. Ledinsky, S. Janz, S. Reber, A. Fejfar, in Proceedings of 27 th European Photovoltaic Conference and Exhibition, 2012, p. 2386

25. S. Reber, W. Zimmermann, T. Kieliba, Sol. Energy Mater. Sol. Cells 65, 409 (2001)
26. T. Kunz, I. Burkert, N. Gawehns, R. Auer, in Proceedings of the 23rd European Photovoltaic Solar Energy Conference, Valencia, Spain, 2008, p. 2202

27. B. Gorka, Ph.D. Thesis, Technical University of Berlin, 2010

28. D.A. Clugston, P.A. Basore, in Proceedings of the 26th IEEE Photovoltaics Specialist Conference, Anaheim, USA, 1997 , p. 207

29. T. Kunz, I. Burkert, R. Auer, A.A. Lovtsus, R.A. Talalaev, Y.N. Makarov, J. Cryst. Growth 310, 1112 (2008)

30. V. Gazuz, M. Muehlbauer, M. Scheffler, R. Weissmann, R. Auer, in Proceedings of 21st European Photovoltaic Solar Energy Conference and Exhibition, Dresden, Germany, 2006, p. 851

31. A. Slaoui, A. Barhdadi, J.C. Muller, P. Siffert, Appl. Phys. A 39, 159 (1986)

32. F. Granek, A. Weeber, K. Tool, R. Kinderman, P. de Jong, in Conference Record of the 2006 IEEE 4th World Conference on Photovoltaic Energy Conversion, 2006, p. 1319

33. J. Dore, S. Varlamov, M.A. Green, IEEE J. Photovolt. 5, $9(2015)$

Cite this article as: Da Li, Stephan Wittmann, Thomas Kunz, Taimoor Ahmad, Nidia Gawehns, Maik T. Hessmann, Jan Ebser, Barbara Terheiden, Richard Auer, Christoph J. Brabec, Recrystallized thin-film silicon solar cell on graphite substrate with laser single side contact and hydrogen passivation, EPJ Photovoltaics 6, 60301 (2015). 